\title{
Revolutionizing Gender: Mariela Castro MS \\ Director, National Sex Education Center, Cuba
}

\author{
Gail Reed MS
}

Medicine, social conditions, culture and politics are inextricably bound as determinants of health and wellbeing. In Cuba, perhaps this is nowhere more evident than in the arduous struggle to consider non-discriminatory analysis of gender-sensitive components as fundamental to population health, medical practice and research; national policy; and above all, public consciousness. Among the standardbearers of this cause is Mariela Castro, psychologist and educator with a master's degree in sexuality, who directs the National Sex Education Center (CENESEX), its journal Sexologia y Sociedad, and the National Commission for Comprehensive Attention to Transsexual People. The Center's work is at the vortex of national polemics on sexuality, approaches to sex education and health, and respect for the human rights of people of differing sexual orientations and gender identities.

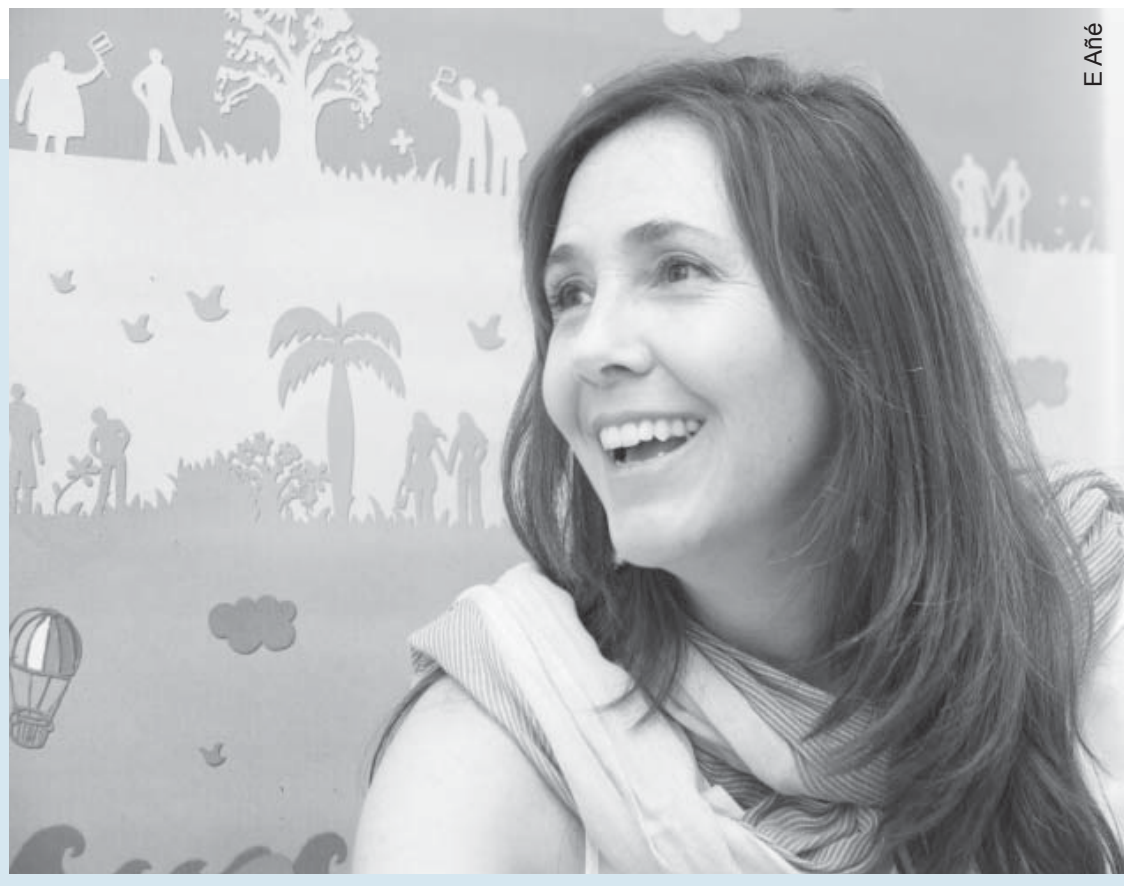

The daughter of President Raúl Castro and the late Vilma Espín-who, as founder and leader of the Federation of Cuban Women, pioneered the defense of both women and homosexuals-Mariela Castro nevertheless speaks with her

own voice in national as well as international debates. MEDICC Review talked with her about the range of issues that link gender to WHO's broad definition of health as the highest level of physical and mental wellbeing.

\section{MEDICC Review: How would you define gender perspective?}

Mariela Castro: I understand gender perspective as a methodological approach that allows you to identify the needs and peculiarities of femininity and masculinity from biological, anthropological, psycho-social and socio-cultural angles. It does so in order to take them into account for interpreting reality and establishing policy.

Although we are all of the same species, we are a "sexed" species. But that isn't the end of the story: we also need to analyze the historical and cultural constructs built upon birth-assigned sex, which produce either wellbeing or discomfort, depending on how the assigned sex is lived from the point of view of power relationships. These are gender relations, and they are the basis for inequity, discrimination and inequalities.

MEDICC Review: How were gender issues first introduced into public consciousness and national policies in Cuba?

Mariela Castro: The theme of gender was first associated with women's rights and equality in the early 60s, when women's economic, social and reproductive rights became explicit in the goals and actions of the revolutionary transformations under way. The Federation of Cuban Women (FMC) spearheaded efforts to confront machismo in many arenas and women's empowerment was enhanced; employment opportunities soon opened up, with equal pay for equal work; maternity leave, social security and other important social policies were introduced into law; and in general, women's public participation increased dramatically.

The patriarchal model was in crisis, and paradigms shifted. Old myths and taboos broke down-the idea that virginity was a prerequisite for marriage, that an unmarried older woman was an "old maid," and so on. In fact, such women actually were regarded as people liberated from patriarchal domination! But we were not speaking yet about several important issues: gender-based violence being one of them. Nor were sexual orientation or gender identity on the agenda, since many patriarchal social and cultural norms still prevailed, leading to severe discrimination on these grounds.

In the health field, the notion of gender was limited to ensuring reproductive rights, through family planning counseling, including access to contraception and abortion; as well as activities of the broader Maternal-Child Health Program of the Ministry of Public Health, within the single, universal health system being developed. Of course, it was vitally important to women, as well as to men, that all these services were being offered free of charge. 
In 1975, the Family Code was passed, a law protecting women's and children's rights within the family. For example, it mandated sharing household and child-rearing responsibilities between the man and the woman. But changes at this "micro-social" level proved harder, slower and more difficult, because they struck at the heart of consciousness and cultural values.

\section{MEDICC Review: How would you describe gender's relation to the health sector in Cuba today?}

A gender perspective is a fundamental resource, especially in the health field: it is part of our scientific arsenal to develop evidencebased policies that lead to better health and wellbeing. However, a gender perspective in Cuban health is still a slogan, not a reality. It is an aspiration, which we haven't yet managed to implement, for lack of a comprehensive approach. A rigorous gender perspective is still lacking; the analysis fails to include all the necessary components.

On the statistical front, health data collected include some valuable elements, but not all. Sex, age, skin color, geographic residence-these are all being considered. But not gender: what it means to be a woman or a man in our society and its effect on health.

In assessing health problems, a sexual-gender focus would consider gender and the lifelong roles based on that gender assigned to each person. It would also take into account, for example, the evolution of the Cuban family: today, more women are heads of households; same-sex couples form households; the grandmother isn't content any longer just to be the "rearguard" for the rest of the family, but rather has her own plans. Interestingly, we are also seeing more men taking greater responsibility for their children, taking paternity more seriously.

In health, we have to face the high costs of gender stereotypingwhich render both men and women more vulnerable-in terms of morbidity and mortality. For example, take cancer, diabetes or other chronic illnesses, the main causes of death and disability in Cuba. Their prevalence, context, and expression aren't the same for men as for women. More specifically, consider lung cancer: rates are higher among men, who also smoke more. But women's lung cancer incidence has also shown rising tendencies, and their smoking habit is not declining as fast as men's. Why is this? We need to know.

The same is true of diet and exercise: our country's obesity and overweight problem is primarily among women. Why? Does it have to do with the "second shift," in which most women still shoulder the main burden of household responsibilities after they return from their paying jobs?

A woman gets home from work, cooks dinner and prepares snacks for her children's school the next day. She's also the one who usually reviews the children's homework. She may be an activist in her community, too, in the FMC, or have a leadership role at work or in her community. Meaning she even has an intellectual overload to contend with. So when does she get to go dancing, participate in other cultural activities or do regular exercise? She's too tired, and often simply alienated. These are just some of the factors that need to be considered from a gender perspective in order to confront the dangers of obesity among women.
MEDICC Review: What about gender stereotyping of men and its effect on their health?

In Cuban society, the traditional concept of masculinity is a real danger to men's health. The stereotype says that men who go to the doctor must be weak-so they only go at the last minute, when their conditions have already progressed. If their ailment has to do with their genitalia, their sexual potency, then they put the doctor's visit off even further. And in the meantime, they may even tend to blame their female partners for their affliction.

MEDICC Review: Since CENESEX was founded in 1989, it has been dedicated to formulating and changing sex education programs in the country, building on earlier momentum created by the FMC and the National Task Force on Sex Education. What has been achieved? What are the challenges?

By way of background, the National Sex Education Program receives the most support from MINSAP and, in the realm of civil society, from the FMC - the latter has really led the field throughout the decades-and we also work with the Ministries of Education (MINED) and Culture (MINCULT), as well as other entities.

At first, there was strong resistance by officials in education to offering sex education in the schools at all. In the 1970s, only a few references to reproductive health could be found in textbooks, and they were very biologically oriented. In the 1980s, researchers identified the need to learn and teach about sexuality, and some movement took place. For example, sex education was introduced as a subject in all of the university-level teachertraining schools in the country. I was a student at one, and I liked the subject so much that later it became one of those I taught.

Finally, in 1996, the National Sex Education Program for Cuban schools was developed by CENESEX and MINED, with participation by the Ministry of Culture. It started out very tentatively; "sex education light." It didn't include a comprehensive, integrated concept of sexuality, omitting themes of diversity for example. Today, their inclusion is still timid, and some resistance persists.

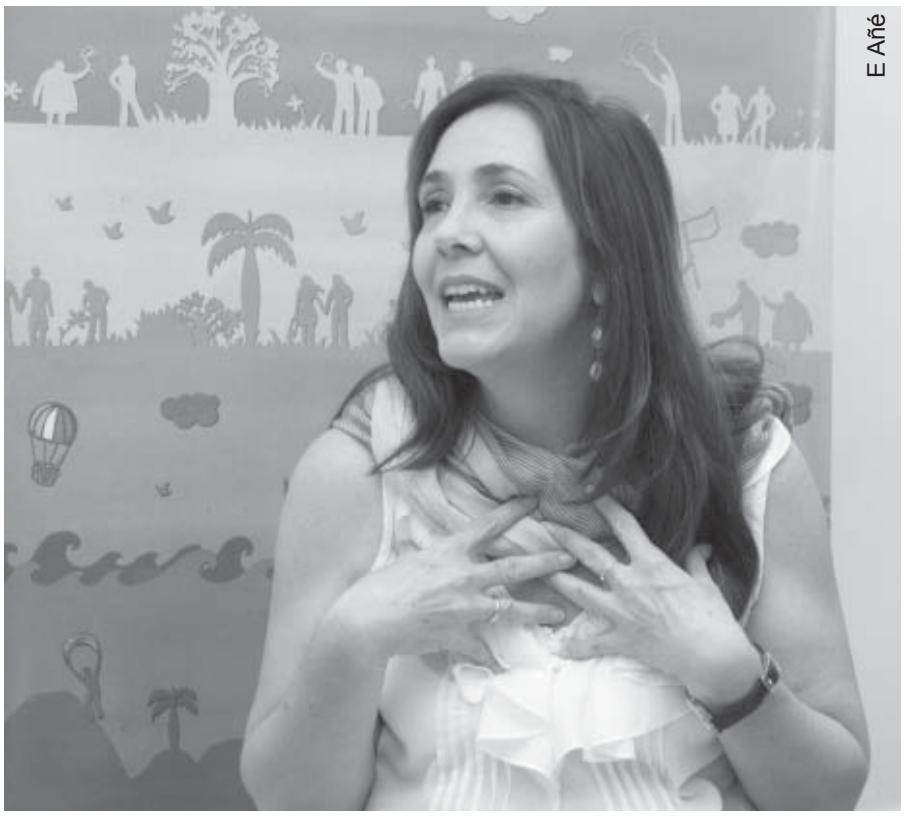


From a 2008 MINSAP-MINED initiative, an agreement was reached called "Prevention through Education," providing a very good approach. It concentrates on STI-HIVIAIDS prevention, involves CENESEX, the National STI-HIVIAIDS Prevention Center, MINED, the Ministry of Higher Education and others, in a process of appreciative inquiry. This resulted in a working group to look more closely at school curricula, social communication and legislation. The group has proposed that sex education be included as a separate subject in the core curriculum for teacher training. It had been eliminated from the pedagogical universities; and to date, sex education in the technical-level teacher-training schools is still scattered throughout other subjects, which isn't working. What is needed is a complete review of the sex education programs in all schools.

Last year, a new MINED resolution mandated sex education in schools from nursery through high school, but again, not as a separate subject. And that is its Achilles heel: because when these themes are incorporated throughout all subjects, their treatment is more vulnerable to the teachers' own level of awareness_or lack thereof-and bias. In addition, it doesn't provide for work with families, a strategic starting point.

\section{MEDICC Review: What about sex education as a} subject in medical schools?

Mariela Castro: CENESEX has proposed a project to promote sexual health throughout the national health system. It has been well received, and we expect implementation soon. We're beginning with courses for medical school faculty, built on a series of rightsbased themes emerging from eight goals that define a comprehensive approach to sexual health promotion.

These objectives were proposed by the World Association for Sexual Health as a contribution to achieving the Millennium Development Goals. They include conceptualization and specific actions to: 1) Recognize, promote, ensure and protect sexual rights for all; 2) Advance toward gender equality and equity; 3) Condemn, combat and reduce all forms of sexuality related violence; 4) Provide universal access to comprehensive sexuality education and information; 5) Ensure that reproductive health programs recognize the centrality of sexual health; 6) Halt and reverse the spread of HIVIAIDS and other sexually transmitted infections; 7) Identify, address and treat sexual concerns, dysfunctions and disorders; and 8) Achieve recognition of sexual pleasure as a component of holistic health and wellbeing.

We'll be using popular education methodology, which will also be applied by faculty in subsequent courses offered to students in medical and other health sciences studies, as well as to physicians completing their residencies in family medicine. Our hope is that the Cuban and nearly 20,000 international students in Cuba's medical schools will be able to use this knowledge and popular education approach in their communities in Cuba and abroad upon graduation-respecting cultural and ethnic differences-to promote sexual health and responsible sexual conduct.

\section{Cuba's Celebrations against Homophobia 2012 Main Events}

\begin{abstract}
Havana
Opening ceremonies for the International Day against

Homophobia (IDAHO): Remarks by CENESEX director Mariela

Castro and Miguel Barnet, President, Cuban Union of Writers

\& Artists. Followed by: book and magazine launchings, panels,

lectures and closing concert
\end{abstract}

Evening: Cabaret show hosted by Abraham Bueno Garcia, Transformista

Workshop on Rights to Sexual Orientation in the Caribbean; Opening, Women, Gender and Rights international conference. University of Havana School of Law

Evening: Cuban Gala against Homophobia, Karl Marx Theater

Audiovisuals, panels, ecumenical celebration against

homophobia, plays, fashion show, and all-day free and confidential HIV testing

La Rampa, along $23^{\text {rd }}$ Street, Vedado District

Diversity Fiesta, University Beach House

Public community debates:

"Combating stigma and discrimination"

23 and G Streets, Vedado District

Workshops, University of Havana, Information Sciences University and Higher Institute of Pedagogical Studies

Evening: Show hosted by transformista Riuber Alarcón (Margot)

Cienfuegos

Panel and debate, Pedagogical University of Cienfuegos

Social networks workshops, Martí Central Park

Evening: Megaconcert by Kfé Mezclao and guest performers

Celebration of International Day against Homophobia

Public community debates against homophobia, Cienfuegos

Central Promenade.

Parade along Central Promenade

May 17 Lecture by Mariela Castro, Medical University of Cienfuegos

Open Forum, Carlos Rafael Rodríguez University

Evening: Gala against Homophobia, Tomás Terry Theater Diversity Fiesta, Casa de la Música

May 22-25 LGBTI Film Series: Cine Club Diferente

MEDICC Review: Gender-based violence and domestic violence in general was long absent from the media and public discussion in Cuba, but now we are seeing much more in the newspapers, on television, etc.

Mariela Castro: Yes, and more needs to be done. Thus far, our studies show that psychological violence, rather than physical or economic violence, is more common in Cuba. Why? First, because women have achieved relative economic independence, and divorce is thus not only an option, but one chosen more often as compared to other countries (the reasons for choosing divorce are multi-factorial of course). Second, when there is a case of violence against a woman, child or elderly person in Cuba, the community tends to get involved. The family doctor as well. Nevertheless, violence is embarrassing to the victim, who feels defenseless, vulnerable and ashamed all at once. It often takes 
that person time to seek help, if they do at all. And there is no place in the world that has dedicated sufficient resources for victims to find immediate help. Nowhere.

Cuban laws are quite harsh against domestic abuse; but learning how to recognize psychological abuse and how to deal with it is another matter, which depends on education through organizations like CENESEX and through the mass media.

MEDICC REVIEW: How has the focus on gender-related issues changed in public discourse, debate and law in more recent years?

Mariela Castro: Historically, the FMC has been a leader in this process: in its last Congress, discussion focused for the first time on the need to include gender-sensitive and discrimination issues in training for people in public administration and political leadership, in conjunction with focusing on other inequalities.

By the middle of the last decade, CENESEX had adopted a human rights approach to the debate on respect for free sexual orientation and gender identity. Thus, in our social communication strategy, we're consciously seeking a cultural transformation based on identifying homophobia and transphobia as forms of discrimination. In 2008, joint efforts with MINSAP and others resulted in a resolution mandating comprehensive care for transsexual persons.

Importantly, in January of this year, the Communist Party Conference stipulated as an objective its aim to "confront prejudices and discriminatory conduct on the basis of sexual orientation" (and in practice, on the basis of gender identity).

Still our biggest challenge is to achieve greater influence on formulation of social and public policies addressing gender equity. For instance, we have proposed legislation that would allow transsexual persons to change their identity without sex-reassignment surgery. And we have worked on amendments to the Family Code, currently under consideration by Parliament, which we expect to be approved this year. These amendments would more forcefully guarantee the rights of women, children, disabled persons and older adults in the family context; further democratize gender roles; and recognize the legal rights of same-sex couples. Furthermore, CENESEX has proposed an article respecting sexual orientation and gender identity.

MEDICC Review: For the past five years, CENESEX has led the organization of annual Cuban Celebrations against Homophobia in May. Can you tell us more about this year's events?

Mariela Castro: In 2008, we began celebrating "days" against homophobia, essentially as an educational forum. Over time, this has turned out to be an entire month dedicated to activities against homo- and transphobia. We've found it useful to hold the main events in different provinces each year-last year in Santiago de Cuba, which was a wonderful experience, and this year in Cienfuegos. Of course, we'll also have activities in Havana and elsewhere in the country.

Last year's public debates, open to everyone in parks and other venues, resulted in something very special, which we're continuing this year [see Program in box-Eds]. And the gala as well. We need more support from the media in publicizing the month, and in general in giving greater visibility to efforts against homo- and transphobia. The social networks associated with CENESEX are very active, and provide a good example of what is possible, but the national media, which reaches the whole population, is still an underutilized educational tool.

We hope the 2012 Celebration Against Homophobia will contribute to national discussions on prejudice of all kinds still present in Cuba that contribute to inequities-not just sexual orientation and gender identity, but also about discrimination based on skin color, religious beliefs, where someone lives, disabilities or any other....none of these have any place in our society, now or in the future. -1 - 